\title{
GAMBARAN TEMUAN AUTOPSI KASUS TENGGELAM DI BLU RSU PROF. DR. R. D. KANDOU MANADO PERIODE JANUARI 2007 - DESEMBER 2011
}

\author{
Rifino A. Wulur \\ Johannis F. Mallo \\ Djemi Ch. Tomuka
}

Bagian Ilmu Kedokteran Forensik Fakultas Kedokteran Universitas Sam Ratulangi Manado Email: fhyno91@yahoo.com

\begin{abstract}
Drowning is one of asphyxia caused by the entry of fluid into the respiratory tract. Approximately $0.7 \%$ of all deaths worldwide or more than 500,000 deaths each year are caused by drowning. Increased access to water is another risks factor for drowning. Manado is a city located on the seaboard and is a risk factor for drowning. The purpose of this research was to know the description of autopsy findings in drowning cases in Prof. Dr. R. D. Kandou General Hospital Manado Period January 2007 - December 2011. The research method used was a descriptive retrospective using secondary data obtained from the Forensic Medicine Prof. Dr. R. D. Kandou General Hospital Manado. Based on inclusion criteria, sample that gained was 15 cases. The highest incidence occurred in 2010. Based on the characteristics of case, obtained $80 \%$ for men and about $86.67 \%$ in the group of adults. Autopsy findings are mushroom-like mass (13.33\%), women's hand wash (13.33\%), cadaveric spasm (6.67\%), foreign material in airways and gastrointestinal (93.33\%), signs of asphyxia (100\%), lung secretion positive examination (100\%), and sign of other violence (86.67\%).
\end{abstract}

Keywords: forensic medicine, autopsy findings, drowning

\begin{abstract}
Abstrak: Tenggelam merupakan salah satu jenis asfiksia yang disebabkan masuknya cairan kedalam saluran pernapasan. Sekitar 0,7\% kematian di seluruh dunia atau lebih dari 500.000 kematian setiap tahun disebabkan karena tenggelam. Peningkatan akses terhadap air merupakan salah satu faktor risiko tenggelam. Manado merupakan kota yang terletak dipesisir pantai dan merupakan faktor risiko terjadinya tenggelam. Tujuan dari penelitian ini untuk mengetahui Gambaran Temuan Autopsi Kasus Tenggelam di BLU RSU Prof. Dr. R. D. Kandou Manado Periode Januari 2007 - Desember 2011. Desain penelitian yang digunakan yaitu deskriptif retrospektif dengan menggunakan data sekunder yang diperoleh dari bagian Ilmu Kedokteran Forensik BLU RSU Prof. Dr. R. D. Kandou Manado. Kriteria inklusi yaitu kasus mati tenggelam yang diautopsi. Berdasarkan kriteria inklusi didapatkan sampel sebanyak 15 kasus. Insiden tertinggi terjadi pada tahun 2010. Berdasarkan karakteristik kasus, didapatkan $80 \%$ terjadi pada laki-laki dan sekitar 86,67\% terjadi pada kelompok dewasa. Temuan autopsi yaitu mushroom-like mass (13,33\%), washer women's hand (13,33\%), cadaveric spasm $(6,67 \%)$, benda asing dalam saluran napas dan pencernaan $(93,33 \%)$, tanda asfiksia (100\%), pemeriksaan getah paru positif (100\%), dan tanda kekerasan lain $(86,67 \%)$.
\end{abstract}

Kata Kunci: kedokteran forensik, temuan autopsi, tenggelam

Tenggelam merupakan salah satu jenis asfiksia yang disebabkan masuknya cairan kedalam saluran pernapasan. ${ }^{1}$ Kematian akibat tenggelam merupakan salah satu hal yang sulit di diagnosis dibidang ilmu kedokteran forensik, terutama bila korban yang ditemukan sudah dalam keadaan membusuk. $^{2,3}$ Pada keadaan membusuk pemeriksaan seringkali tidak menunjukkan tanda yang khas. Diagnosis tenggelam dapat dicapai setelah mempertimbangkan semua hasil pemeriksaan forensik meliputi 
pemeriksaan luar, pemeriksaan dalam, dan laboratorium. ${ }^{1,2}$

\section{Menurut World Health Organization}

$(W H O) \quad 0,7 \% \quad$ dari seluruh

kematian didunia atau lebih dari 500.000

kematian setiap tahun disebabkan karena tenggelam. ${ }^{4}$ Pada tahun 2004 diseluruh dunia terdapat 388.000 orang meninggal karena tenggelam, angka ini menempati urutan ke-3 kematian didunia akibat cedera tidak disengaja ${ }^{5}$ dan menurut Global Burden of Disease (GBD) bahwa angka tersebut sebenarnya lebih kecil dibanding seluruh kematian akibat tenggelam yang disebabkan oleh banjir, kecelakaan transportasi laut, dan bencana lainnya.,

Pada anak umur 4 tahun kebawah memiliki angka kematian tertinggi di dunia yang biasanya terjadi di kolam renang atau di bak mandi. ${ }^{5,7,8}$ Berdasarkan data statistik dari Centers for Disease Control and Prevention $(C D C)$ risiko tertinggi tenggelam terjadi pada umur 1-4 tahun dan menurun pada umur 5-14 tahun. Pada umur 15 tahun terjadi peningkatan secara substansial dan terus meningkat sepanjang umur. $^{9}$

Anak laki-laki disebutkan 2-4 kali lebih sering mengalami kejadian tenggelam dibandingkan dengan anak perempuan. ${ }^{8} \mathrm{Hal}$ ini disebabkan karena laki-laki lebih sering mengalami paparan dengan air seperti berenang sendiri, mengkonsumsi alkohol sebelum berenang dan berperahu. ${ }^{5}$

$$
\text { Secara umum } 90 \% \text { kasus }
$$
tenggelam terjadi di air tawar (danau, sungai, kolam) dan $10 \%$ terjadi di air laut. Tenggelam di dalam cairan lain jarang terjadi dan biasanya merupakan kecelakaan kerja. $^{10}$

Afrika menempati posisi terbanyak kasus tenggelam didunia dan lebih dari sepertiga kasus terjadi di kawasan Pasifik, sedangkan Amerika merupakan kawasan yang mengalami kasus tenggelam terendah. Angka kematian tenggelam di Afrika delapan kali lebih tinggi dibanding Amerika dan Australia. ${ }^{6}$

Kejadian di negara berkembang lebih tinggi dibanding negara maju. Di negara berkembang seperti Indonesia angka kejadiannya belum dapat diketahui pasti. ${ }^{4}$

Peningkatan akses terhadap air merupakan salah satu faktor risiko tenggelam. Individu dengan pekerjaan seperti penangkap ikan komersial atau memancing dengan menggunakan perahu kecil lebih rentan terhadap tenggelam. ${ }^{5}$ Sekitar $43 \%$ kasus tenggelam terjadi pada waktu rekreasi. Kasus tenggelam sering terjadi saat musim liburan khususnya pada tempat wisata laut dan rerata korbannya yaitu wisatawan. ${ }^{9}$

Wilayah Indonesia terdiri atas daratan dan lautan dengan luas wilayah lautan sebesar 6,1 juta $\mathrm{km}^{2}$ atau sekitar $77 \%$ dari wilayah Indonesia. $^{11}$ Menurut Kementerian Kelautan dan Perikanan, saat ini persentase nelayan di Indonesia mencapai $25 \%$ dari jumlah penduduk tanah air. ${ }^{12}$ Penelitian yang dilakukan oleh Ivan N dkk, didapatkan bahwa jenis kecelakaan transportasi laut yang sering terjadi adalah tenggelam. ${ }^{13}$

Manado merupakan kota yang terletak di tepi pantai laut Sulawesi, dimana wilayah lautnya sering digunakan oleh para nelayan sebagai tempat mencari nafkah. Profesi nelayan di Kota Manado mencapai 9,17\% dan menempati urutan ke-4 dari keseluruhan profesi masyarakat Manado. Laut Manado juga merupakan tempat wisata mulai dari rekreasi pinggir pantai, snorkilling sampai dengan selam scuba. ${ }^{14}$

Tenggelam merupakan penyebab utama mortalitas dan morbiditas yang tidak disengaja. Namun tingkat mortalitas dan morbiditas akibat tenggelam yang sebenarnya sulit ditentukan karena banyaknya kasus yang tidak dilaporkan dan banyaknya korban yang tidak mendapat pelayanan medis. $^{10}$

\section{METODE PENELITIAN}

Jenis penelitian yang digunakan adalah deskriptif retrospektif dengan menggunakan hasil visum yang diperoleh di bagian Ilmu Kedokteran Forensik BLU RSU Prof. Dr. R. D. Kandou Manado. Sampel yang diambil yaitu data kasus mati tenggelam dari Januari 2007 - Desember 
2011 dengan kriteria inklusi kasus mati tenggelam yang diautopsi. Variabel yang akan diteliti antara lain; jumlah kasus, jenis kelamin, umur, dan temuan autopsi.

\section{HASIL DAN PEMBAHASAN}

Tabel 1. Jumlah kasus kematian akibat tenggelam yang dilaporkan di BLU RSU Prof. Dr. R. D. Kandou Periode Januari 2007 - Desember 2011

\begin{tabular}{ccc}
\hline Tahun & $\begin{array}{c}\text { Jumlah } \\
\text { Kasus }\end{array}$ & \% \\
\hline 2007 & 0 & 0 \\
2008 & 2 & 13,33 \\
2009 & 5 & 33,33 \\
2010 & 7 & 46,67 \\
2011 & 1 & 6,67 \\
\hline Total & $\mathbf{1 5}$ & $\mathbf{1 0 0}$
\end{tabular}

Dari data yang diperoleh didapatkan 15 kasus tenggelam yang diautopsi. Insiden kematian akibat tenggelam tertinggi pada tahun 2010 yaitu 7 kasus $(46,67 \%)$ dan terendah pada tahun 2007 tidak ada kasus.

Tabel 2. Distribusi berdasarkan jenis kelamin

\begin{tabular}{ccc}
\hline $\begin{array}{c}\text { Jenis } \\
\text { Kelamin }\end{array}$ & $\begin{array}{c}\text { Jumlah } \\
\text { Kasus }\end{array}$ & \% \\
\hline Laki-laki & 12 & 80 \\
Perempuan & 3 & 20 \\
\hline Total & $\mathbf{1 5}$ & $\mathbf{1 0 0}$
\end{tabular}

Dari data distribusi kasus tenggelam berdasarkan jenis kelamin, didapatkan bahwa laki-laki lebih banyak meninggal akibat tenggelam yaitu sebanyak 12 kasus (80\%) dibandingkan dengan perempuan hanya 3 kasus (20\%). Hasil ini sesuai dengan data dari World Health Organization (WHO), ${ }^{5}$ National Safe Kids Campaign (NSKC), ${ }^{8}$ Centers for Disease Control and Prevention $(C D C)^{9}$ yang menyatakan bahwa laki-laki lebih sering mengalami kejadian tenggelam dibandingkan perempuan. Penelitian yang dilakukan oleh Ria Fitricia di RSUP $\mathrm{H}$. ADAM MALIK/RSUD PIRNGADI MEDAN pada januari 2007 - Desember 2009 mendapatkan hasil yang sama. ${ }^{15} \mathrm{Hal}$ ini dapat disebabkan karena laki-laki lebih sering mengalami paparan dengan air dan adanya perilaku-perilaku berisiko seperti berenang sendiri, minum alkohol sebelum berenang sendirian dan berperahu. ${ }^{5,7}$

Tabel 3. Distribusi berdasarkan umur

\begin{tabular}{ccc}
\hline Umur & $\begin{array}{c}\text { Jumlah } \\
\text { Kasus }\end{array}$ & \% \\
\hline$\leq 4$ tahun & 0 & 0 \\
$5-14$ tahun & 1 & 6,67 \\
15-19 tahun & 0 & 0 \\
$\geq 20$ tahun & 13 & 86,67 \\
Tidak & 1 & 6,67 \\
diketahui & & \\
\hline Total & $\mathbf{1 5}$ & $\mathbf{1 0 0}$ \\
Dari data distribusi kasus tenggelam
\end{tabular}
berdasarkan kelompok umur, didapatkan bahwa kasus terbanyak terjadi pada umur $\geq$ 20 tahun yaitu sekitar $86,67 \%$. Hasil ini juga sesuai dengan data statistik dari Centers for Disease Control and Prevention $(C D C)$ yang menyatakan bahwa terjadi peningkatan kejadian tenggelam pada umur dewasa. ${ }^{9}$ Hal ini dapat disebabkan karena kelompok dewasa lingkup aktivitasnya lebih luas, berbeda dengan anak-anak dan remaja masih didalam pengawasan dan lingkup aktivitasnya masih terbatas. Alkohol juga merupakan salah satu penyebab kasus tenggelam pada kelompok dewasa. Sekitar 30-50\% kasus tenggelam pada kelompok dewasa didapatkan dalam keadaan mabuk. ${ }^{10}$ Lokasi Kota Manado yang terletak di pesisir pantai merupakan faktor risiko terjadinya tenggelam.

\section{A. Temuan Autopsi}

Tabel 4. Distribusi frekuensi temuan autopsi kasus tenggelam

\begin{tabular}{cccc}
\hline No. & Temuan Autopsi & $\begin{array}{c}\text { Jumlah } \\
\text { Kasus }\end{array}$ & $\%$ \\
\hline 1 & Tubuh basah & 0 & 0 \\
2 & Mushroom-like mass & 4 & 26,67 \\
3 & Cadaveric spasm & 1 & 6,67 \\
4 & washer women's & 2 & 13,33 \\
$\quad$ hand & & \\
5 & Bercak paltauf & 2 & 13,33 \\
6 & Benda asing dalam & 14 & 93,33 \\
& saluran napas dan & & \\
& pencernaan & & \\
7 & Tanda kekerasan lain & 13 & 86,67 \\
8 & Tanda asfiksia & 15 & 100 \\
9 & Getah paru positif & 15 & 100 \\
\hline
\end{tabular}


Dari data temuan autopsi pada kasus tenggelam, tidak semua tanda-tanda khas tenggelam ditemukan. Contohnya, tanda tubuh basah tidak ditemukan pada kasus. Hal ini dapat disebabkan adanya tindakan awal dari pihak keluarga atau pihak lain seperti pembersihan dan mengganti pakaian korban sebelum diserahkan ke bagian ilmu kedokteran forensik untuk diautopsi.

Busa halus di mulut dan didalam saluran napas (mushroom-like mass) hanya ditemukan pada 4 kasus $(26,67 \%)$. Terbentuknya busa halus tersebut disebabkan karena masuknya cairan dalam saluran pernapasan, merangsang terbentuknya mukus. Substansi ini ketika bercampur dengan air dan surfaktan dari paru-paru dan terkocok oleh karena upaya bernapas yang hebat. Hal ini menandakan bahwa korban masih hidup waktu ada dalam air. ${ }^{16}$ Pada pemeriksaan yang tidak ditemukan mushroom-like mass, mungkin dapat disebabkan adanya tindakan awal dari keluarga seperti pembersihan mayat sebelum diserahkan ke bagian forensik untuk di autopsi dan dapat juga disebabkan karena mayat yang diperiksa sudah dalam keadaan membusuk.

Tanda cadaveric spasm, washer woman's hand, dan bercak paltouf akan sulit terlihat bila jenazah sudah dalam keadaan membusuk. Proses pembusukan tersebut disebabkan karena mayat korban lama ditemukan sehingga pada saat pemeriksaan, mayat sudah dalam keadaan membusuk. ${ }^{16}$

Tanda Cadaveric spasm hanya ditemukan pada 1 kasus $(6,67 \%)$. Hal ini merupakan tanda bahwa korban berusaha untuk menyelamatkan diri dengan memegang apa saja seperti rumpur, dahan, batu atau benda-benda lain dalam air. ${ }^{1,16}$ Tanda washer woman's hand hanya ditemukan pada 2 kasus $(13,33 \%)$. ini merupakan suatu keadaan dimana tangan dan kaki berkeriput yang disebabkan karena imbibisi cairan kedalam kutis dan biasanya membutuhkan waktu yang lama. ${ }^{1}$ Bercak paltouf ditemukan pada 2 kasus $(13,33 \%)$. Terbentuknya bercak ini disebabkan karena robeknya partisi inter alveolar yang sering terlihat dibawah pleura dengan warna biru kemerahan. ${ }^{16}$

Pasir, lumpur, dan tumbuhan air sering dijumpai pada saluran napas bahkan sampai ke saluran pencernaan. Hal ini dapat disebabkan korban menghirup dan menelan benda-benda tersebut sewaktu didalam air. ${ }^{1,16}$ Berdasarkan temuan autopsi didapatkan sebanyak 14 kasus $(93,33 \%)$.

\section{SIMPULAN}

Setelah dilakukan penelitian ini diperoleh simpulan bahwa laki-laki 4 kali lebih tinggi angka mati tenggelam dibandingkan dengan perempuan. Kasus tenggelam terbanyak terjadi pada kelompok dewasa. Pada temuan autopsi, tanda yang khas sering tidak ditemukan. Pemeriksaan getah paru positif pada semua kasus dan sampai saat ini masih menjadi gold Standard dalam mendiagnosis kasus kematian akibat tenggelam.

\section{SARAN}

Diharapkan dapat menjadi masukan bagi pemerintah dalam menciptakan upaya penanggulangan korban tenggelam agar tidak meningkat mengingat lokasi Kota Manado yang berada dipesisir pantai. Diharapkan adanya penelitian lebih lanjut secara analitik menganai kasus tenggelam.

\section{UCAPAN TERIMA KASIH}

Terima kasih ditujukan kepada dr. Johannis F. Mallo, SH, SpF, DFM, DK, dr. L. Ratulangi, SpF, Dr. dr. Erwin Kristanto, $\mathrm{SH}, \mathrm{SpF}$ sebagai penguji dan semua pihak yang secara langsung maupun tidak langsung telah memberikan ide/gagasan dalam penyelesaikan skripsi ini.

\section{DAFTAR PUSTAKA}

1. Budiyanto A, Widiatmo $\mathbf{W}$, Sudiono S, Winardi T, Mun'im A Sidhi, Hertian S, et al. Ilmu kedokteran forensik. Ed I. Jakarta: Bagian Kedokteran Forensik Fakultas Kedokteran Universitas Indonesia; 1997. 
2. Farrugia A, Ludes B. Diagnostic of drowning in forensic medicine. Prof. Duarte Nuno Vieira, Editor. Forensic Medicine - From Old Problem to New Challenges; 2011 [cited 2011 sept]. Available from: http://cdn.intechopen.com/pdfs/19161/I nTech-

Diagnostic_of_drowning_in_forensic medicine.pdf

3. Shiwei M, Feng F, Dong $\mathbf{X}$, Seese RR, Wang Z. A contributory diagnosis of drowning in putrefactive corpses using the electric impedance spectroscopy. Rom J Leg Med [18]. 2010. p $283-88$.

4. Szpilman D, Bierens JJLM, Handley AJ, Orlowski JP. Drowning. Review article. $n$ engl j med 366;22. 2012.

5. World Health Organization. Drowning. Fact sheet N*347; 2012 [cited 2012 Oct]. Available from: http://www.who.int/mediacentre/factsh eets/fs347/en/

6. Amril. Tatalaksana penderita tenggelam. Majalah Farmacia. Edisi April 2007; 2007 [cited 2012 Oct 26]. Available from: http://www.majalahfarmacia.com/rubrik/one_news.asp?ID News $=439$

7. Rip Current Safety. Facts about injuries drowning. 2011. Available from

http://www.ripcurrents.noaa.gov/resour ces/DrowningFactSheetWHO2.pdf

8. National Safe Kids Campaign. Drowning. Washinton: NSKC; 2004. Available from http://www.preventinjury.org/pdfs/dro wning.pdf.

9. Centers for Disease Control and Prevention. Drowning risks in natural water settings. CDC; 2012 [cited 2012 June 13]. Available from: http://www.cdc.gov/Features/dsDrowni ngRisks/

10. Shepherd SM. Drowning. Norris RL, Talavera F, Lang ES, Evans BJ, editors. Medscape reference; 2011 [cited 2011 Aug 23]. Available from: http://emedicine.medscape.com/article/ 772753-overview

11. Basuki I, Sembiring E, Safitriani D, Simanjuntak D. Sumber daya laut indonesia dan pengelolaannya. 2009. Available from: http://images.ibasoke.multiply.multiply content.com/attachment/0/SktgkgoKCt YAACJ0bdA1/Laut\%20Indonesia.pdf

12. Situmorang N. Pendidikan untuk kesejahteraan nelayan. Kementerian Kelautan dan Perikanan Republik Indonesia; 2012. Available from: http://www.kkp.go.id/index.php/arsip/c /7233/Pendidikan-untuk-

Kesejahteraan-Nelayan/

13. Nathanael I, Guming ROS, Pitana T. Analisa keselamatan awak kapal berdasarkan konsep the maritime labour convention 2006 dirute penyeberangan ketapang-gilimanuk. Department of Marine Engineering, Faculty of Marine Technology, Sepuluh Nopember Institute of Technology; 2006.

14. Wikipedia. Kota manado; 2012 [cited 2012 Oct 25]. Available from: http://id.wikipedia.org/wiki/Kota Man ado

15. Fitricia R. Tanda intravital yang ditemukan pada kasus tenggelam di departemen kedokteran forensik fk usu rsup h. Adam malik/rsud pirngadi medan pada bulan januari 2007 desember 2009 [Skripsi]. Medan: FK USU; 2010.

16. Idries AM. Pedoman ilmu kedokteran forensik. ed I. Jakarta: Binarupa Aksara; 1997. 